\title{
Thermodynamics Study on Liquid Phase Catalytic Exchange for Water Detritiation
}

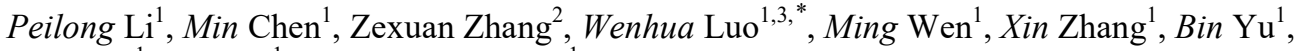 \\ Fei Jiang ${ }^{1}$, Yan $\mathrm{Shi}^{1}$ and Jiangfeng Song ${ }^{1}$ \\ ${ }^{1}$ Institute of Materials, China Academy of Engineering Physics, P.O. Box 9071, Mianyang 621907, \\ Sichuan, China \\ ${ }^{2}$ School of Physics Science and Technology, Xinjiang University, Urumqi 830046 \\ ${ }^{3}$ Science and Technology on Surface Physics and Chemistry Laboratory, P.O. Box 9072-35, \\ Mianyang 621908, Sichuan, China
}

\begin{abstract}
Liquid phase catalytic exchange (LPCE) is one of the key technologies for tritium removal of tritiated water, such as effluents from Fukushima nuclear power plant. Although former researchers have widely studied this process theoretically, the reported results differ from each other due to different assumptions and parameters adopted. In this work, the principle of Gibbs free energy minimization is applied, with only basic physical properties and no more other assumptions involved. The predictions of isotope exchange are more accurate, and the average error between calculation results and experimental data reduces from $4.45 \% \sim 6.65 \%$ to $2.17 \%$. Then the catalytic exchange behaviors are systematically investigated in the protium-deuterium (H-D) system, and the influence of the cascade processes are emphatically analyzed. The method established in this paper could be applied to catalytic exchange systems for tritium separation, which is essential for the development of water detritiation.
\end{abstract}

\section{Introduction}

Tritium is a radioactive isotope of hydrogen, which is hazardous to the human body and the environment. The disposal of tritiated water is a crucial important technology to the development of nuclear power and fusion energy [1-3]. Recently it has aroused wide attention and discussion that Japanese Government decides to discharge the wastewater of Fukushima nuclear power plant, in which tritium is the most important radionuclide. In addition, the development of fusion energy also meets the challenge of water detritiation, fusion power plants will produce a large amount of tritiated water in detritiation systems and leakage accidents [4]. The efficient water detritiation technique is critical urgent for nuclear industries and fusion energy.

Compared to Vapor Phase Catalytic Exchange (VPCE) and some other processes, liquid phase catalytic exchange (LPCE) has advantages such as moderate operation conditions, simpler process, higher separation factor and lower energy consumption [5-7]. As the

"Corresponding author: luowenhuacaep@126.com 
radioactive property of tritium, it is not practical to carry out systematical tritiumcontaining experimental on LPCE. Then systematical research, especially, establishment of an accurate and reliable model, is crucial for its practical application. Some different models have been applied to describe this process. For example, Zhong et al. [8] reported the separation factor of the H-D system using the ratios of partition functions of the molecules. Ye et al. [9] applied the statistical thermodynamic partition functions and calculated the equilibrium constants. As large numbers of physical parameters are adopted, such as molecular translation, vibration and weight factors, the calculation results differ from experimental results due to the cumulative error of adopted parameters and the deviation of different empirical correlations. Besides, some theoretical model were established considering gas-liquid-vapor phase on theoretical plates [4,10,11], among which Anisia et al. [6,12] developed their model based on the mass transfer characteristics. The parameters in the equilibrium stage models and mass transfer models, such as the number of theoretical plates, packing pressure drop and mass transfer coefficient, are mostly based on experiments, leading calculations very sensitive to parameters' selections. The results reported in different literatures are inconsistent, which may confuse or mislead researchers in related fields. In addition, most reports were mainly focused on the H-D system, lacking the data of tritium-containing system. Hence it is significant to carry out indepth theoretical research on LPCE and establish a method that can accurately forecast the catalytic exchange performance of all hydrogen isotopes.

According to the Gibbs free energy minimization principle, the total Gibbs free energy reaches the minimum when reaction system is in equilibrium. The calculation of thermodynamic equilibrium state involves only basic thermodynamic parameters, which are mainly determined by experiments and could help to improve the accuracy of the theoretical results of LPCE [7,13]. In this work, a theoretical study about the thermodynamic characteristics of LPCE of protium-deuterium (H-D) system was firstly carried out based on the mentioned principle, and much higher prediction accuracy was achieved to benefit for the design of this process. Then the catalytic exchange of hydrogen and water was detailed studied, especially in some cascade processes. The research method established in this paper can be further extended to tritium systems, which shows obvious significance for the future application, and the results for the tritium-containing system would be discussed in our follow-up work.

\section{Research methods}

\subsection{LPCE reaction and equilibrium constant}

The liquid phase catalytic exchange is a coupling of two subprocesses, namely phase transformation and catalytic exchange. The phase transition (denoted as P.T.) process shown in Eq. (1) achieves equilibrium between vapor phase (v) and liquid phase (1), while the catalytic reaction (denoted as C.R.) in Eq. (2) is the catalytic exchange of hydrogen isotopes between water vapor and gas hydrogen. The overall LPCE process realizes the isotopic exchange of protium and deuterium between liquid water and hydrogen gas, as shown in Eq. (3) [7,14].

$$
\begin{aligned}
& \text { P.T.: } \mathrm{HDO}(1)+\mathrm{H}_{2} \mathrm{O}(\mathrm{v}) \leftrightarrow \mathrm{HDO}(\mathrm{v})+\mathrm{H}_{2} \mathrm{O}(1) \\
& \text { C.R.:HDO }(\mathrm{v})+\mathrm{H} 2(\mathrm{~g}) \leftrightarrow \mathrm{HD}(\mathrm{g})+\mathrm{H} 2 \mathrm{O}(\mathrm{v}) \\
& \text { LPCE: } \mathrm{HDO}(1)+\mathrm{H}_{2}(\mathrm{~g}) \leftrightarrow \mathrm{HD}(\mathrm{g})+\mathrm{H}_{2} \mathrm{O}(1)
\end{aligned}
$$


The equilibrium constant for the gas-liquid phase transition process as Eq. (1) is:

$$
K_{\mathrm{P} . \mathrm{T} .}=\left([\mathrm{HDO}]_{\mathrm{v}}\left[\mathrm{H}_{2} \mathrm{O}\right]_{1}\right) /\left([\mathrm{HDO}]_{1}\left[\mathrm{H}_{2} \mathrm{O}\right]_{\mathrm{v}}\right)=p_{\text {ноо }}^{*} / p_{\mathrm{H}_{2} \mathrm{O}}^{*}
$$

where $p_{\mathrm{HDO}}{ }^{*}$ and $p_{\mathrm{H} 2 \mathrm{O}}{ }^{*}$ the corresponding saturated vapor pressure.

As shown in Eq. (2), the equilibrium constant is:

$$
K_{\text {c.R. }}=\left([\mathrm{HD}]_{\mathrm{g}}\left[\mathrm{H}_{2} \mathrm{O}\right]_{\mathrm{v}}\right) /\left([\mathrm{HDO}]_{\mathrm{v}}\left[\mathrm{H}_{2}\right]_{\mathrm{g}}\right)
$$

For the overall LPCE reaction (3), the equilibrium constant is:

$$
K_{\text {LPCE }}=\left([\mathrm{HD}]_{\mathrm{g}}\left[\mathrm{H}_{2} \mathrm{O}\right]_{1}\right) /\left(\left[\mathrm{H}_{2}\right]_{\mathrm{g}}[\mathrm{HDO}]_{1}\right)=K_{\text {P.T. }} \times K_{\text {C.R. }}
$$

\subsection{Principle of Thermodynamic Equilibrium Calculation}

The maximum conversion of the LPCE process is limited by the thermodynamic equilibrium. There is no doubt that thermodynamic results are essential to guide process design and engineering amplification. When calculating of the thermodynamic equilibrium components, the total Gibbs free energy $\left(G_{\text {total }}\right)$ in a reaction system is of great importance, which is obtained based on reaction temperature $T$, pressure $p$ and specific composition conditions, as shown in Eq. (7) [13]:

$$
G_{\text {total }}=\sum_{i} n_{i}\left(\Delta_{\mathrm{f}} G_{i}^{\theta}+R T \ln \left(y_{i} \Phi_{i} p / p^{\theta}\right)\right)
$$

where ni and yi are the molar amount and molar percentage of reactant i, respectively, $\Delta \mathrm{fGi} \theta$ the standard formation Gibbs free energy; $\Phi \mathrm{i}$ the fugacity coefficient, $p^{\theta}$ the standard pressure $(0.1 \mathrm{MPa})$. Within the temperature and pressure focused in LPCE, the system is assumed as an ideal system.

According to the Gibbs free energy minimization principle, partial molar Gibbs free energy equals to 0 when the chemical reaction reaches equilibrium:

$$
\begin{aligned}
& \left(\partial G / \partial n_{i}\right)_{T, p, n_{j}}=0 \quad(i \neq j) \\
& \Delta_{\mathrm{f}} G_{i}^{\theta}=\Delta_{\mathrm{f}} H_{i}^{\theta}-T \Delta_{\mathrm{f}} S_{i}^{\theta}
\end{aligned}
$$

where $C_{\mathrm{p}}$ the isobaric heat capacity. $\Delta_{\mathrm{f}} G_{i}^{\theta}$ is derived from $\Delta_{\mathrm{f}} H_{i}^{\theta}$ and $\Delta_{\mathrm{f}} S_{i}^{\theta} . C_{\mathrm{p}}$, $\Delta_{\mathrm{f}} H_{i}^{\theta}(298.15 \mathrm{~K})$ and $\Delta_{\mathrm{f}} S_{i}^{\theta}(298.15 \mathrm{~K})$ are basic thermodynamic data, which can be found in the relevant data books [15-17].

Based on above principles, we developed the calculation codes in Python, and carried out the following studies. 


\section{Results and discussions}

\subsection{Theoretical calculation and verification}

The equilibrium constant of the phase transition (Eq.(1)) was calculated by the Raoult's law. For a mixed solution system with low deuterium concentration, the law of saturated vapor pressure was summarized as Eq. (10) [9,18]:

$$
K_{\text {P.т. }}=p_{\text {нDо }}^{*} / p_{\mathrm{H}_{2} \mathrm{O}}^{*}=\operatorname{Exp} .\left(-26398.800 / T^{2}+89.607 / T-0.0758\right)
$$

The equilibrium constant $K_{\text {P.T. }}$ defined in Eq. (4) was solved and shown in Fig. 1. With an increased $T(\mathrm{~K}), K_{\text {P.T. }}$ increases but is always $<1$, while the growth rate of $K_{\text {P.T. }}$ decreases. In the LPCE, a higher $K_{\text {P.T. }}$ means a higher concentration of $\mathrm{HDO}(\mathrm{v})$ in the vapor phase, which enhances the driving force of reaction and promotes the catalytic exchange to move toward the positive reaction direction.

In the catalytic reaction process shown in Eq. (5), the equilibrium constant $K_{\text {C.R. was }}$ solved by the Gibbs free energy minimization principle, as listed in Fig. 1. It is clear that $K_{\text {C.R. }}$ almost linearly increases with an increasing $T$ as Eq. (11) $\left(R^{2}=0.9996\right)$ showed:

$$
K_{\text {C.R. }}=0.00138 T-0.123
$$

Base on the basic principles of thermodynamics, the equilibrium constant $K_{\mathrm{LPCE}}$ is the product of $K_{\text {C.R. }}$ and $K_{\text {P.T. }}$ (Fig. 2). As $K_{\text {P.T. }}$ is close to 1 , the trend of $K_{\text {LPCE }}$ with $T$ is similar to that of $K_{\mathrm{C} . \mathrm{R} \text {. }}$.

To verify the accuracy of the calculation results, we summarized several results from present literatures (Fig. 3) $[4,8,9,19,20]$. The average error between calculation results and experimental results is $4.45 \% \sim 6.65 \%$, while calculation method adopted in this work could cut down the deviation by $2.17 \%$. Furthermore, an empirical correlation equation for $K_{\text {LPCE }}$ in H-D system was established as Eq. (12):

$$
K_{\text {LPCE }}(\mathrm{H}-\mathrm{D})=(0.00138 T-0.123) / \text { Exp. }\left(26398.800 / T^{2}-89.607 / T+0.0758\right)
$$

The deuterium abundance of natural hydrogen and water is about $140 \sim 150 \mathrm{ppm}$. Based on the difference in chemical potentials of the deuterium components (HDO and HD) between liquid and gas, the deuterium concentration in hydrogen gas phase could be reduced in LPCE process, and deuterium depleted hydrogen and deuterium enriched water can be produced. Based on the method described above, the LPCE process between water and hydrogen with natural abundance was analyzed below.

Setting the gas and liquid phase molar ratio $G=L=1 \mathrm{kmol} / \mathrm{h}$ and the natural deuterium abundance $150 \mathrm{ppm}$, the reactant concentration and deuterium abundance after a singlestage LPCE reaction under different $T$ were calculated, as shown in Fig. 4 and 5. With $T$ rising, the deuterium concentration $C_{\mathrm{D}}$ of hydrogen gas increases while $C_{\mathrm{D}}$ of liquid phase decreases. For instance, when $T=30^{\circ} \mathrm{C}, C_{\mathrm{D}}$ in hydrogen is as low as $64.7 \mathrm{ppm}$, while that of liquid water is $235.3 \mathrm{ppm}$; when $T=80^{\circ} \mathrm{C}$, the $C_{\mathrm{D}}$ of hydrogen and water are $78.1 \mathrm{ppm}$ and $221.9 \mathrm{ppm}$, respectively. As we mainly concerns the reduction of deuterium or tritium in hydrogen, we introduce the dedeuterium factor $(D F)$ here, defining as the ratio of $C_{\mathrm{D}}$ in inlet hydrogen to that in outlet. Fig. 5 revealed $D F$ at $30^{\circ} \mathrm{C}(2.32)$ is much higher than that at $80{ }^{\circ} \mathrm{C}(1.92)$, suggesting the lower $T$ is conducive to the production of deuterium depleted hydrogen with lower $C_{\mathrm{D}}$. However, it is noteworthy that besides thermodynamic factors, the kinetics factor should also be considered in the actual application. As lower $T$ 
slows down the reaction rate and limits the reaction yield, more catalysts and a higher reactor are needed to achieve higher yields.

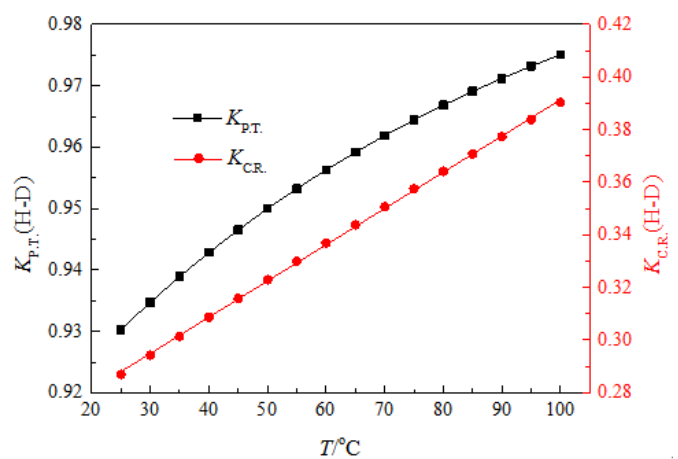

Fig. 1. The equilibrium constant of phase transition and catalytic exchange process

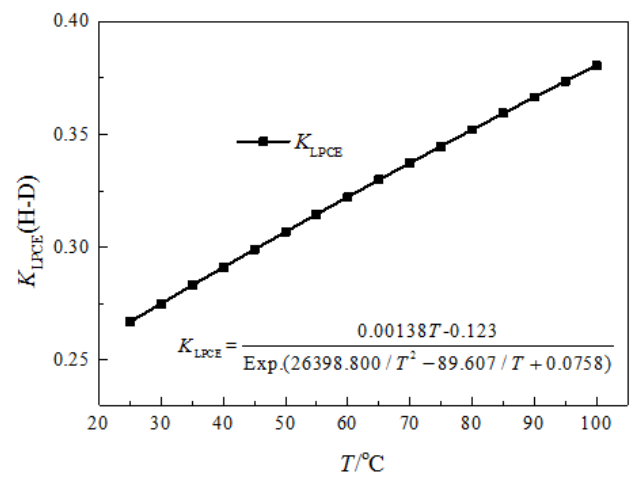

Fig. 2. The equilibrium constant of LPCE in H-D system.

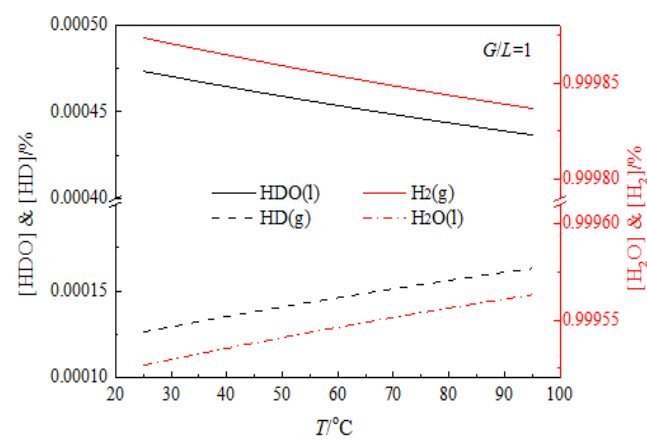

Fig.4. The concentration of reactants with temperature in a single-stage LPCE.

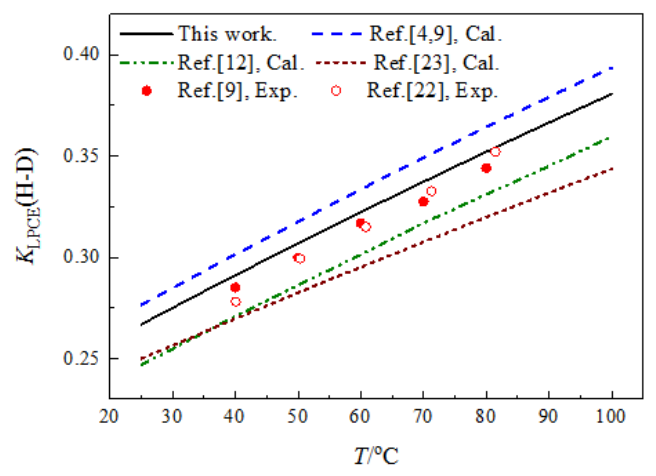

Fig. 3. The comparison of equilibrium constant of LPCE process.

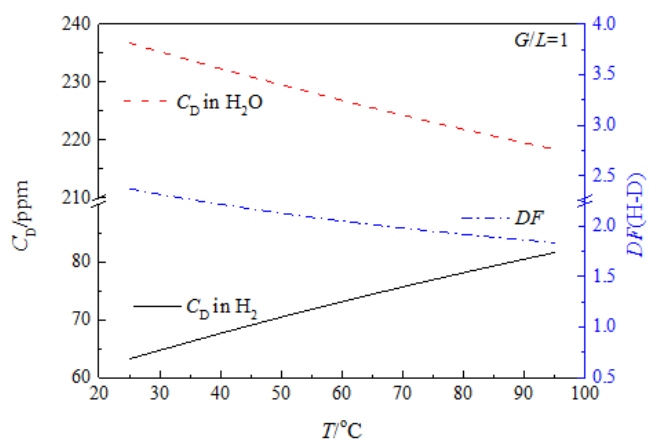

Fig.5. The concentration of deuterium and $D F$ in a single-stage LPCE.

The molar feed ratio of gas over liquid phase $(G / L)$ is also a key factor to LPCE efficiency. Therefore, in this work we investigated the impact of $G / L$ on $D F$, as shown in Fig. 6. Fig. 7 describes the trend of $C_{\mathrm{D}}$ in the gas and liquid phase, showing that $C_{\mathrm{D}}$ in hydrogen increases with $G / L$ rising, while $D F$ declines during the reaction. However, the effect of increasing $G / L$ on $C_{\mathrm{D}}$ gradually weakened, and $D F$ slightly changes when $G / L>8$. In addition, influences of temperature on reactants' concentration and $C_{\mathrm{D}}$ are consistent with Fig. 4 and 5. 


\subsection{Cascade process of LPCE}

In the actual application, the cascade processes are widely used to promote reaction yields. One kind of cascade process (Process 1, P\#1) is given in Fig.8, in which the deuterium depleted hydrogen out of each reactor is input as feed to the next LPCE column, while natural abundance water is used as the liquid raw material into all columns. After the cascade process, the deuterium concentration in hydrogen could be deeply depleted.

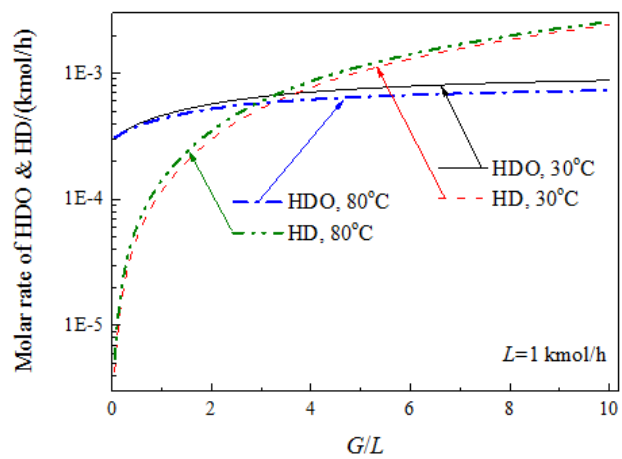

Fig. 6. The concentration of HD and HDO with $\mathrm{G} / \mathrm{L}$ in a single-stage LPCE.

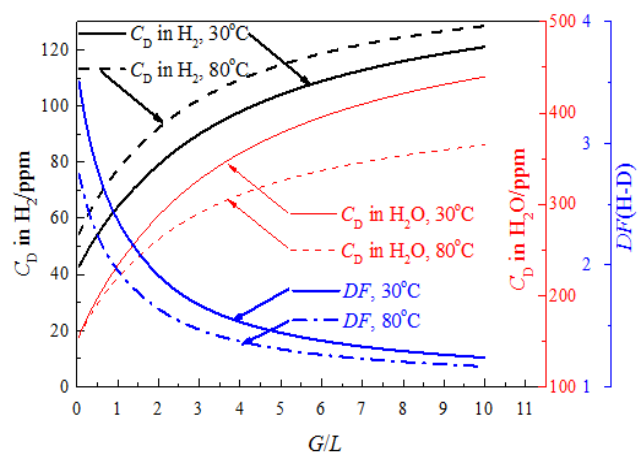

Fig. 7. The deuterium concentration and $D F$ with $\mathrm{G} / \mathrm{L}$ in a single-stage LPCE.

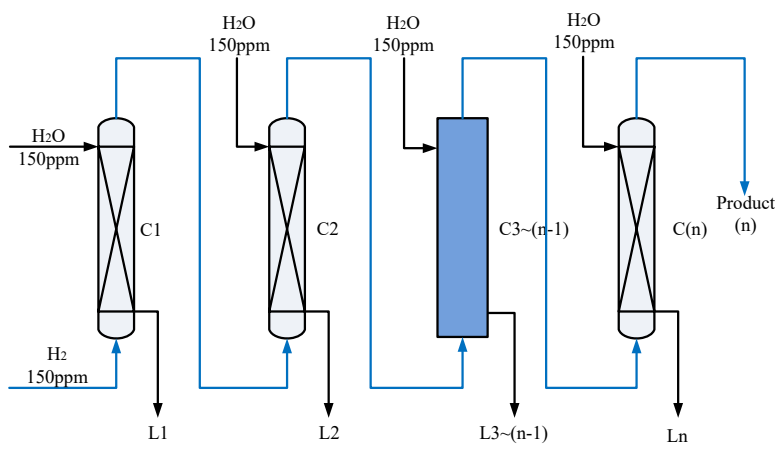

Fig. 8. Flowchart of the cascade process $1(\mathrm{P} \# 1)$

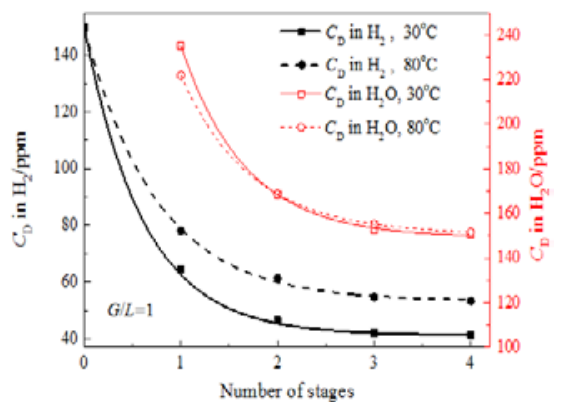

Fig. 9. The deuterium concentration with stage numbers in $\mathrm{P} \# 1$.

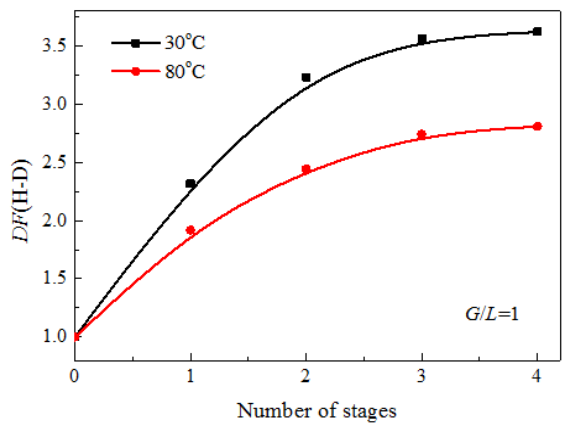

Fig. 10. The overall dedeuterium factor with stage numbers in $\mathrm{P} \# 1$. 
Fig. 9 indicates $C_{\mathrm{D}}$ of product hydrogen and water obtained by cascade process $\mathrm{P} \# 1$ at $30^{\circ} \mathrm{C}$ and $80^{\circ} \mathrm{C}$, with fixed molar feed ratio $G / L=1$. The results signify $C_{\mathrm{D}}$ in hydrogen produced out of each reactor decreases accordingly with stage number increases. For example, $C_{\mathrm{D}}$ in hydrogen outcome of the stage number 1 and 4 are $64.7 \mathrm{ppm}$ and $41.4 \mathrm{ppm}$ at $30{ }^{\circ} \mathrm{C}$, respectively. The corresponding $C_{\mathrm{D}}$ at $80^{\circ} \mathrm{C}$ are $78.1 \mathrm{ppm}$ and $53.4 \mathrm{ppm}$, respectively. However, the decline rate of $C_{\mathrm{D}}$ in hydrogen slows down with increasing stage numbers, and $C_{\mathrm{D}}$ is approaching the minimum with more than 3 towers. The $C_{\mathrm{D}}$ in the product water from each stage also decreases significantly as the stage number increasing. The $C_{\mathrm{D}}$ of deuterium enriched water in the $4^{\text {th }}$ stage is almost close to the natural abundance $\left(150.6 \mathrm{ppm}\right.$ at $30^{\circ} \mathrm{C}$ and $151.6 \mathrm{ppm}$ at $\left.80^{\circ} \mathrm{C}\right) . \mathrm{DF}$ of a 4 -stage cascade process at $30^{\circ} \mathrm{C}$ and $80^{\circ} \mathrm{C}$ reaches 3.6 and 2.8 , respectively, which achieves corresponding limits, as shown in Fig. 10.

In the practical application, $\mathrm{P} \# 1$ could be designed as just a higher column with proper gas-liquid distributors. Although $C_{\mathrm{D}}$ in hydrogen product could be further reduced by decreasing $G / L$ of each stage or operating under a lower $T$, it is limited by thermodynamics and $C_{\mathrm{D}}$ of $<40 \mathrm{ppm}$ could hardly be reached using water and hydrogen with natural abundance, even if the stage number dramatically increases. To break this bottleneck, the kind of auto-oxidation cascade process (Process 2, P\#2) is proposed to further reduce $C_{\mathrm{D}}$ in product, in which process part of deuterium depleted hydrogen is oxidized as the liquid feed of next column with the rest part as gas feed, as shown in Fig. 11.

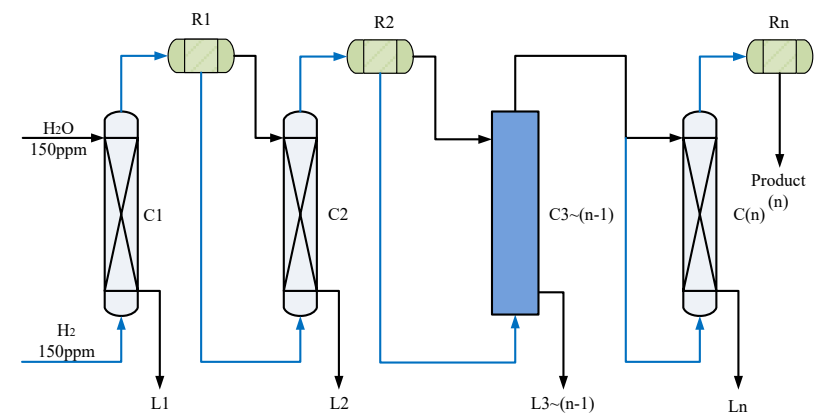

Fig. 11. Flowchart of the auto-oxidation cascade process $2(\mathrm{P} \# 2)$

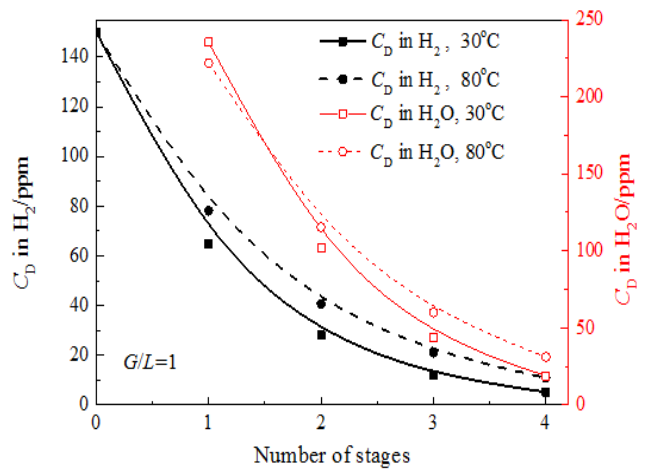

Fig. 12. The deuterium concentration with the number of stages in $\mathrm{P} \# 2$.

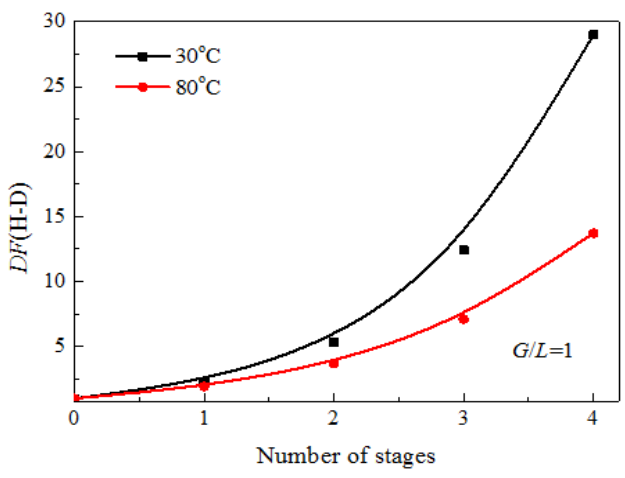

Fig. 13. The overall $D F$ with the number of stages in $\mathrm{P} \# 2$.

Setting $G / L=1$, the $C_{\mathrm{D}}$ in the product hydrogen and water by the process 2 were calculated. As Fig. 12 shows, deuterium depleted hydrogen of $12.1 \mathrm{ppm}$ is generated through a 3 -stage process at $30^{\circ} \mathrm{C}$, comparing with $5.2 \mathrm{ppm}$ in a 4-stage process. While for 
$80^{\circ} \mathrm{C}$, the concentration is $10.9 \mathrm{ppm}$ in a 4-stage process. Meanwhile, the cascade process $\mathrm{P} \# 2$ could produce deuterium depleted products with a wider range of $\mathrm{CD}$ covering from 5.2 to $115.4 \mathrm{ppm}$. By just adjusting the stages and other operating conditions, it is practical to meet the concentration requirements of deuterium depleted products.

The comparison of Fig. 10 and Fig. 13 indicates a significant difference of $D F$ between $\mathrm{P} \# 1$ and $\mathrm{P} \# 2$. DF of $\mathrm{P} \# 1$ increases with the cascade stages. When the $\mathrm{P} \# 1$ with 4 stages, $D F$ are $3.62\left(30^{\circ} \mathrm{C}\right)$ and $2.81\left(80^{\circ} \mathrm{C}\right)$, respectively. However, $D F$ in $\mathrm{P} \# 2$ shows an exponential growth, with $D F 28.97$ and 13.72 at $30^{\circ} \mathrm{C} 80^{\circ} \mathrm{C}$, respectively, which are much higher than that of $\mathrm{P} \# 1$. Although the lowest deuterium depleted hydrogen production of $\mathrm{P} \# 2$ is only $1 / 2 \mathrm{n}$ of that of $\mathrm{P} \# 1$ as the stage number increases, the deuterium concentrations of gas and water produced from the second and later stages in $\mathrm{P \# 2}$ are all lower than natural abundance, and exhibit wider concentration distribution from $5.2 \mathrm{ppm}$ to $115.4 \mathrm{ppm}$. In addition, it should be noted that the amount of total deuterium depleted product in $\mathrm{P} \# 2$ at different concentrations, including hydrogen and water, is consistent with P\#1.

\section{Conclusion}

In this paper, the key equilibrium parameters of the H-D system were obtained by the principle of Gibbs free energy minimization for LPCE process. Compared with the experimental results, the calculation accuracy was improved, and the error between calculation and experimental results reduced from $4.5 \% \sim 5.6 \%$ in the literatures to $2.17 \%$, and corresponding empirical correlation was proposed. Further, based on this model, the impacts of operating conditions and two kinds of cascade processed on H-D separation efficiency were studied. The results proved that the multi-stage auto-oxidation cascade process showed the obvious advantage of producing deuterium depleted products with wider concentration distribution, for instance, ranging from 5.2 to $115.4 \mathrm{ppm}$ with 4 stages.

The calculation model and research method established in this paper can be extended to tritium systems, which can simultaneously calculate the catalytic reaction characteristics of different hydrogen isotopes $\left(\mathrm{H}_{2}, \mathrm{HD}, \mathrm{HT}, \mathrm{D}_{2}, \mathrm{DT}, \mathrm{T}_{2}\right)$ and oxides $\left(\mathrm{H}_{2} \mathrm{O}, \mathrm{HDO}, \mathrm{HTO}, \mathrm{D}_{2} \mathrm{O}\right.$, $\mathrm{DTO}, \mathrm{T}_{2} \mathrm{O}$ ). It is helpful to in-depth understand of LPCE process and greatly facilitate the research and industrial application.

\section{Acknowledgements}

The authors gratefully acknowledge the supports by the National Key Research and Development Program of China (2017YFE0300302), Sichuan Science and Technology Program (2020YFQ0005).

\section{References}

[1] Xu YP, Huang YJ, Qin CL, Zhang XF, Chen CF and Shangguan ZH 2012 Radiat. Prot. Bull. 32(3) 16-21 ( In Chinese)

[2] Gao F, Yang LJ and Pan YL2016 J. Nucl. Radiochem. 38(1) 52-5 (In Chinese)

[3] Technical requirements for discharge of radioactive liquid effluents from nuclear power plant 2011 GB14587-2011 (In Chinese)

[4] Ye LS, Luo DL, Tang T, Yang W and Yang Y 2015 Fusion Eng. Des. 100 576-80

[5] Ye LS, Luo DL, Yang W, Guo WS, Xu QY and Jiang CL 2013 Int. J. Hydrogen Energy 38(31) 13596-603

[6] Bornea A, Peculea M, Zamfirache M and Varlam C 2005 Fusion Eng. Des. 48 116-9 
[7] Li PL, Guo L, Xiong RJ, Wen M, Yao Y, Zhang Z, Song JF, Shi Yan and Tang T 2019 Chin. J. Chem. Eng. 27(8) 1837-45

[8] Zhong ZK, Zhang L, Sun Y, Chen YL and Zhu ZH 2004 Atom. Energy Sci. Technol. 38 148-51

[9] Ye LS 2014 Preparation and performances of hydrophobic catalysts for hydrogenwater isotopic exchange (Hefei: University of Science and Technology of China) $p$ 26

[10] Sugiyama T, Tanaka M, Munakata K, Asakura Y, Uda T, Yamamoto I, Cristescu I and Doerr L 2008 Fusion Eng. Des. 83 1442-6

[11] Ye LS, Luo DL, Tang T, Yang W and Zhao P 2014 Int. J. Hydrogen Energy 39 6604-9

[12] Bornea A, Petrutiu C and Zamfirache M 2015 Fusion Eng. Des. 67 270-3

[13] Li PL and Wang TF 2015 Chin. J. Chem. Eng. 23 681-8

[14] Sugiyama T, Asakura Y, Uda T, Abe Y, Shiozaki T, Enokida Y and Yamamoto I 2004 J. Nucl. Sci. Technol. 41 696-701

[15] Daubert TE and Danner RP 1985 Data compilation tables of properties of pure compounds (New York: American Institute of Chemical Engineers)

[16] Chase MW 1998 NIST-JANAF thermochemical tables, 4th edition (American Institute of Physics)

[17] Yaws CL 2001 Matheson gas data book, 7th edition (Parsippany: McGraw-Hill)

[18] Van Hook W. Alexander1968 J. Phys. Chem. 72(4) 1234-44

[19] Rolston JH, Hartog JD and Butler JP1976 J. Phys. Chem. 80(10) 1064-7

[20] Yamanishi T and Okuno K 1994 JAERI-Data/Code 94-019 